\title{
Pseudoaneurysm of profunda femoris artery: a rare complication after intramedullary fixation for an intertrochanteric femur fracture
}

\author{
Vicky T. Jain ${ }^{1} *$, Jeetendra Katariya ${ }^{1}$, Shreedhar Archik ${ }^{2}$ \\ Department of Orthopaedics, ${ }^{1}$ Global Hospital, Parel, ${ }^{2}$ Global, Hinduja Hospital, Mumbai, Maharashtra, India
}

Received: 08 April 2019

Accepted: 11 June 2019

*Correspondence:

Dr. Vicky T. Jain,

E-mail: vickrulz11@yahoo.co.in

Copyright: $\odot$ the author(s), publisher and licensee Medip Academy. This is an open-access article distributed under the terms of the Creative Commons Attribution Non-Commercial License, which permits unrestricted non-commercial use, distribution, and reproduction in any medium, provided the original work is properly cited.

\begin{abstract}
Intertrochanteric fracture fixation with a trochanteric femoral nail rarely leads to any vascular or neurological complications. The aim of this case report is to identify a patient with post-operative Pseudoaneurysm of profunda femoris artery and how to manage it. We report a case of 79-year-old male who developed a Pseudoaneurysm of the profunda femoris artery 3 days after intramedullary femoral nailing for a intertrochanteric femur fracture. Percutaneous embolization was performed with subsequent resolution of the symptoms. Diagnosis of vascular complications after hip surgery may be very challenging because symptoms are often nonspecific. Despite their rarity, it is important to know this type of complications to address the diagnostic pathway in the right direction and to treat them promptly.
\end{abstract}

Keywords: Pseudoaneurysm, Traction, Profunda femoris artery, Calcified

\section{INTRODUCTION}

Pseudoaneurysm represents a haematoma that forms as a result of an incomplete disruption of the artery. This haematoma, formed outside the arterial wall, eventually recanalizes to form the pseudoaneurysm which consists of a perfused sac contained by fibrous capsule connected to the artery by a "neck". In clinical practice, it is usually caused by penetrating injuries, interventional diagnostic or therapeutic procedures involving an arterial puncture, or infections. ${ }^{2}$ Pseudoaneurysm of the profunda femoris artery following dynamic hip screw fixation of intertrochanteric femoral fracture is a rare occurrence. ${ }^{3-8}$ However, it warrants greater emphasis to allow differentiation from other postoperative complications like deep vein thrombosis and to prevent its life- or limbthreatening consequences. A possibility of pseudoaneurysm must be entertained by the treating surgeon in such cases to arrive at a correct diagnosis.

\section{CASE REPORT}

A 79 year old male presented to the casualty with history of fall at home and had pain in the right hip region. He was not able to stand on his own. His right lower limb was externally rotated with lateral border of foot touching the bed. On examination he had tenderness at right hip and greater trochanter and painful on attempted passive movements. No swelling or haematoma noticed in or around the outer or inner aspect of thigh. Digital radiograph showed an intertrochanteric fracture of femur (Boyd and Griffin type 2) and calcified vessels in the proximal thigh (Figure 1). On admission his blood reports were haemoglobin of $5.5 \mathrm{~g} / \mathrm{dl}$ with normal coagulation profile.

On day 3 of admission, after two PCV of blood with a haemoglobin of 8.8 , a closed reduction and fixation with a trochanteric femoral nail $12 \mathrm{~mm}$ in diameter and 235 $\mathrm{mm}$ in length with a lag screw of $105 \mathrm{~mm}$ was inserted 
under image intensification which barely lasted for 20 minutes.
Intraoperative and immediate postoperative period was uneventful. Post-operative radiographs were satisfactory.
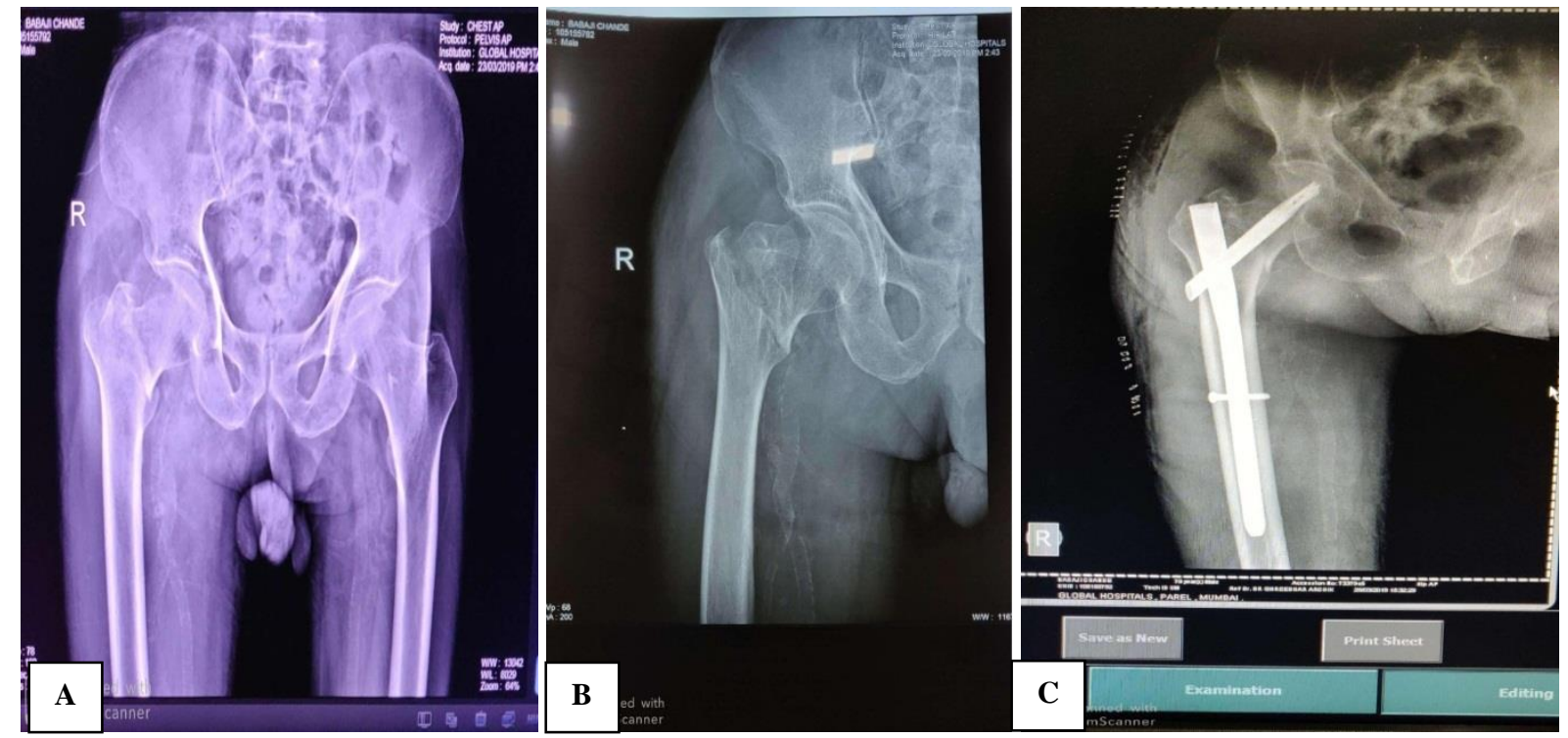

Figure 1: Intertrochanteric fracture in AP (A), lateral view (B) and post-operative radiograph (C) and calcified vessels medially.
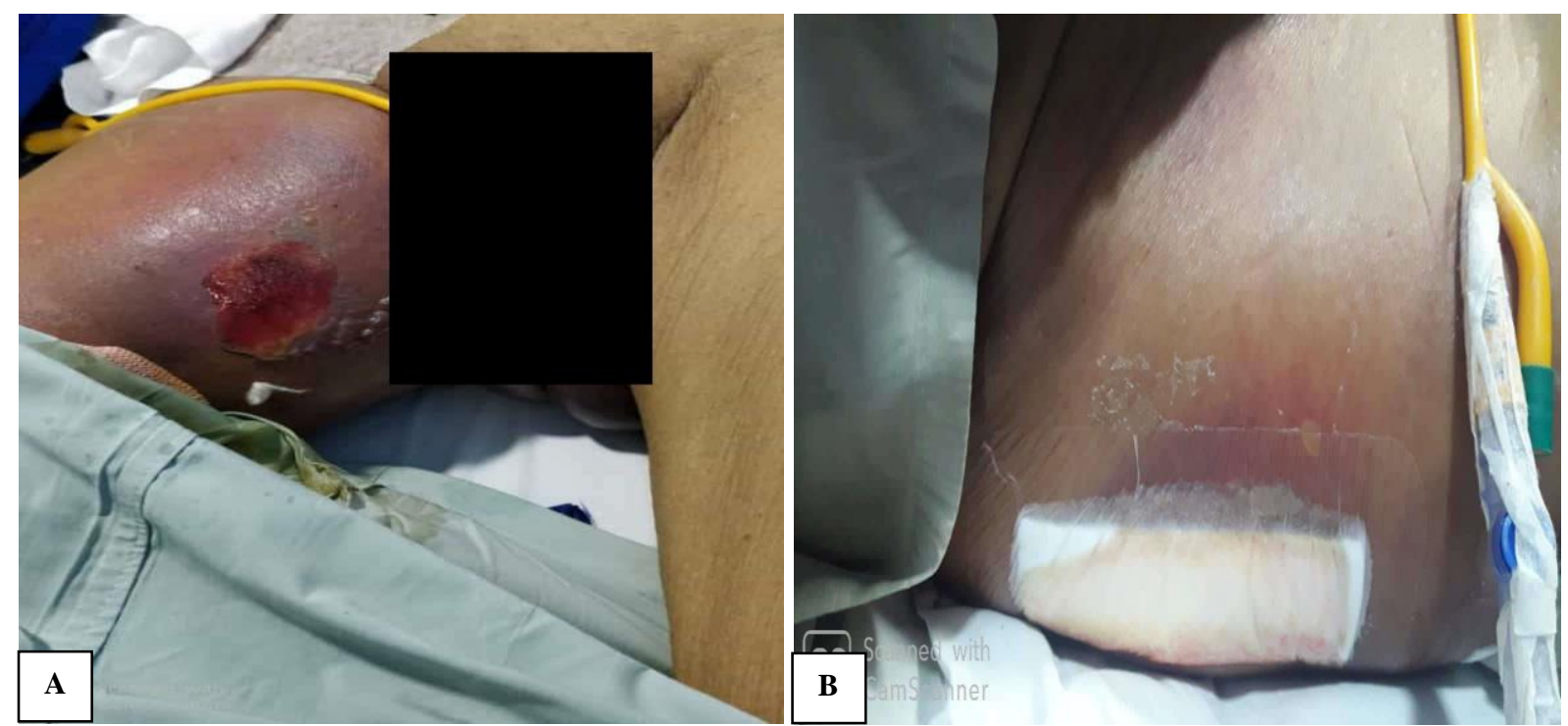

Figure 2: (A) Swelling and collection in thigh and (B) soakage of dressing.

On post-operative day 1 , his haemoglobin was $9.1 \mathrm{~g} / \mathrm{dl}$, no soakage, vital normal, comfortably mobilized with walker.

On post-operative day 2, check dressing done, suture line healthy and no oozing from operative site. The swelling was first noted in inguinal area and hence it was confusing as there were no screws or retractors there. There was a possibility of a tiny aneurysm pre operatively as the haemoglobin was way below normal at $5 \mathrm{~g} / \mathrm{dl}$. There was no long screw insertion either to suspect iatrogenic injury to profunda femoris artery.
On post-operative day 3, there was soakage of dressing and tense swelling on inner aspect of thigh with severe pain, no fever and no neurovascular deficit. Patient underwent ultrasonography suggestive of huge collection (Figure 2) on the inner aspect of thigh about $400 \mathrm{ml}$ which was in solid state with drop in haemoglobin to 4.1 g/dl. Two PCV of blood transfused on the same day. Following the blood transfusion there was persistent drop in haemoglobin with increase in swelling and pain. Haematologist opinion was taken to rule out any coagulopathy or bleeding disorder. 


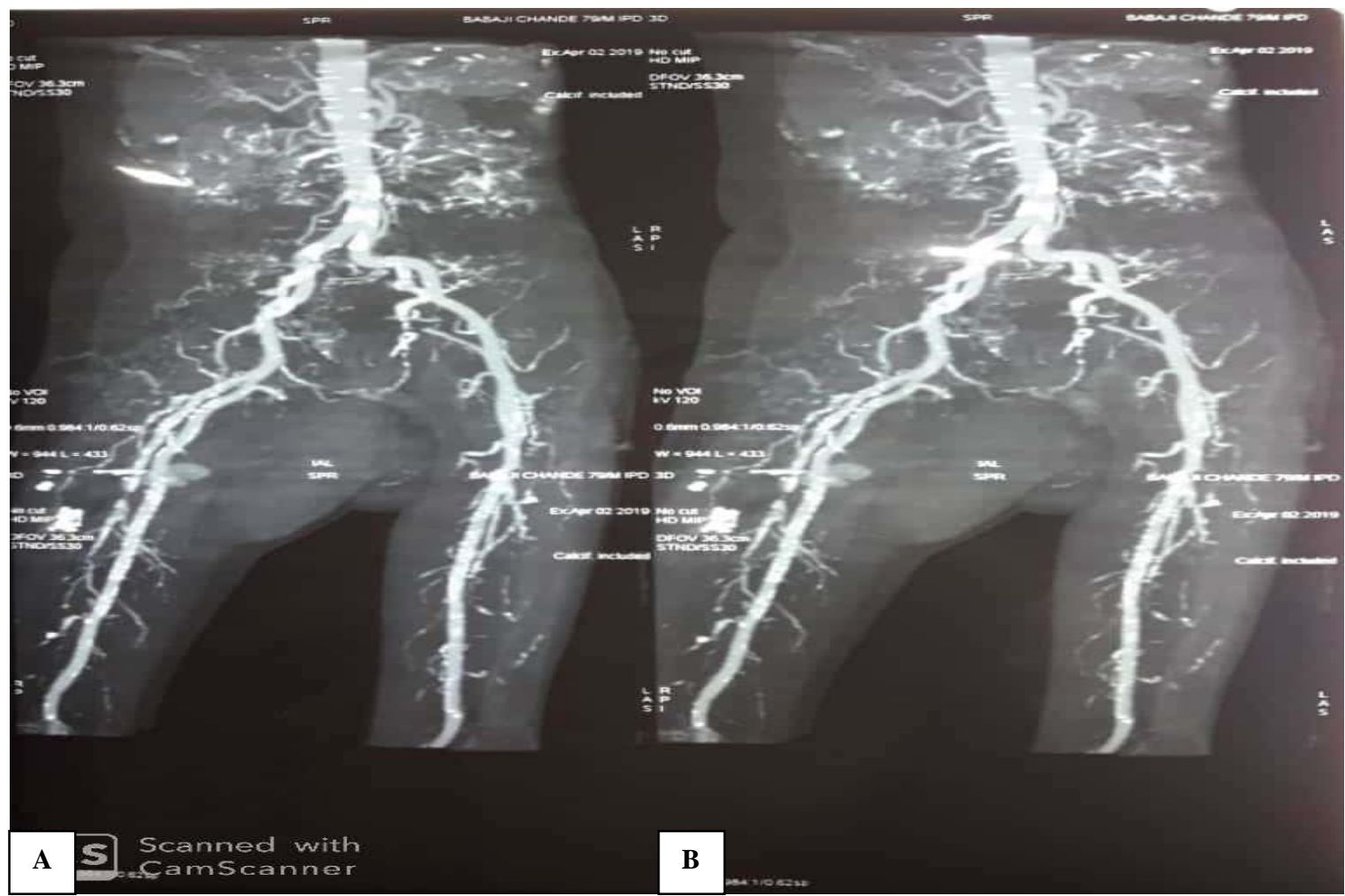

Figure 3 (A and B): CT angiography showing pseudoaneurysm in the right profunda femoris artery.
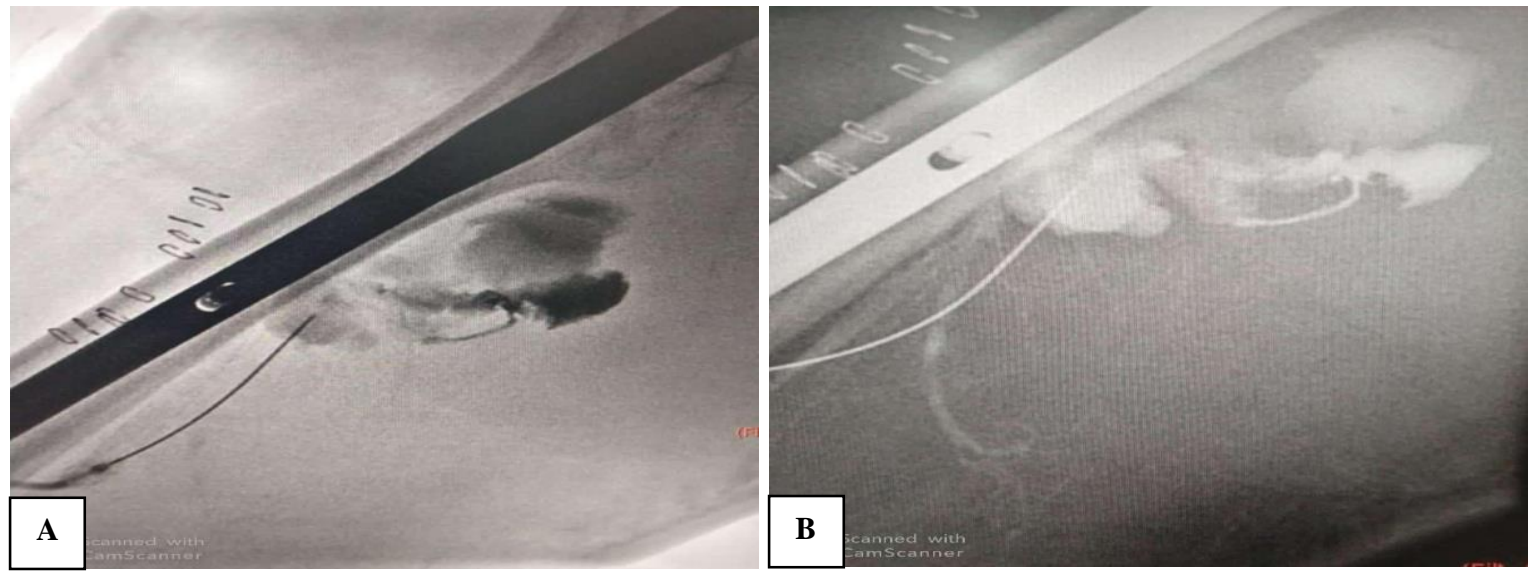

Figure 4 (A and B): Ultrasonogrphy guided embolisation at the pseudoaneurysmal site using thombin.

On post-operative day 7 , repeat local ultrasonography was done which was suggestive of haematoma with pseudo aneurysm which was confirmed on CT angiography. Intervention radiologist did a percutaneous embolization by injecting thrombin at the pseudo aneurysmal site under ultrasonography guidance fig 4 . Post embolisaion patient was stable.

On day 2 post embolization, swelling reduced became soft, pain reduced, no soakage with haemoglobin $9.1 \mathrm{~g} / \mathrm{dl}$ next morning

A repeat ultrasonography was done the next day which showed reduced haematoma and complete obliteration of pseudo aneurysmal site with good flow in profunda femoris artery.no leakage of blood through the embolised pseudo aneurysmal site.

\section{DISCUSSION}

False aneurysms or pseudo aneurysms are surrounded by a thin fibrous capsule in contrast to true aneurysms that consist of the true layers of the arterial wall. The fibrin capsule is made of soft tissues and/or hematoma adjacent the vessel. There is a high risk of enlargement and rapture of the vessel, in particular, when the dimension of the pseudoaneurysm is superior to $3 \mathrm{~cm}$. Rapid expansion, infection, skin or soft tissue necrosis, neuropathy, distal ischemia, pain, or rupture are the most important indications for repair. ${ }^{9}$ 
Vascular injuries following intertrochanteric fracture have been sporadically reported with the extremely rare occurrence $(0.49 \%) .{ }^{10}$

These lesions are usually due to drilling, screw insertion, sometimes to the incorrect introduction of the guide wire in nailing but can also occur by the fracture in itself. ${ }^{11}$ There is a possibility of rupturing the already calcicifed artery seen on the pre-operative and post-operative radiograph by traction injury while trying to align the fracture on a traction table.

Several mechanisms have been incriminated in their genesis: ${ }^{12}$

- The irritation of the arterial wall by a pointed instrument (pin, screw, drill, retractor) represents one of the hypotheses. This is usually a technical error when inserting a too long screw or when a counterbend or a pin is escaping. This is the most reported mechanism in the literature.

- Intimate contact between the small, poorly synthesized trochanter and the artery itself may also be irritating.

- Exaggerated tractions of a curarized patient may result in the rupture of a plaque of atheroma or rupture under adventitious tissue, which will later be responsible of a weakening of the artery wall. The elongation and torsion mechanism is the most incriminated.

- Deep infections.

- In addition, an initial post-traumatic rupture of the arterial wall cannot be ruled out.

Yang has reported a case of pseudo-aneurysm of the superficial femoral artery following closed nailing of a femur fracture possibly due to excess adduction and internal rotation of the limb. ${ }^{13}$

In this case, we found the pseudoaneurysm 7 days after surgery, below the average reported in literature. Often it is difficult to identify this complication because of nonspecific symptoms including pain, edema, and swelling that are common after hip surgery. We should suspect a pseudoaneurysm if the patient presents falling of hemoglobin level, pulsatile swelling, or venous engorgement, and we can diagnose this complication by duplex ultrasound (US), conventional angiography, and computed tomography (CT) angiography. ${ }^{14}$

US is the method of choice for diagnosis of pseudoaneurysm with sensitivity between 94 and $97 \%$. As in our case, conventional angiography (or CTangiography) can be useful to confirm and to better define the vascular lesion.

In our case, we treated a 31-A2 fracture with a gamma nail. The role of intramedullary fixation for the treatment of this kind of fracture is still debated. Anyway, gamma nail is often preferred to slide hip screws, especially, because of easy handling instrumentarium and implant versatility. According to many authors, gamma nail has proved to be a safe and efficient fixation of pertrochanteric fractures. ${ }^{15}$

\section{CONCLUSION}

Pseudo aneurysm of profunda femoris artery after hip surgery is rare but known complication. Early diagnosis by clinical examination like swelling, soakage of dressing and persistently dropping haemoglobin confirmed by ultrasound or CT angiography helps in treating the patient with no complications and can prove lifesaving in this type of complication. Traction injury to the calcified vessels intra-operatively could probably be one of the important causes leading to pseudoaneurysm.

\section{Funding: No funding sources \\ Conflict of interest: None declared \\ Ethical approval: Not required}

\section{REFERENCES}

1. Ahmad F, Turner SA, Torrie P, Gibson M. Iatrogenic femoral artery pseudoaneurysms - a review of current methods of diagnosis and treatment. Clin Radiol. 2008;63(12):1310-6.

2. Dhal A, Chadha M, Lal H, Singh T, Tyagi S. Encounters with pseudoaneurysms in orthopaedic practice. Injury. 2001;32(10):771-8.

3. Dameron TB Jr. False aneurysm of femoral profundus artery resulting from internal fixation device (screw). J Bone Joint Surg Am. 1964;46:57780.

4. Chan WS, Kong SW, Sun KW, Tsang PK, Chow HL. Pseudoaneurysm and intramuscular haematoma after dynamic hip screw fixation for intertrochanteric femoral fracture: a case report. J Orthop Surg (Hong Kong). 2010;18(2):244-7.

5. Abraham E, Pankovich AM, Jansey F. False aneurysm of the profunda femoris artery resulting from intertrochanteric fracture. A case report. J Bone Joint Surg Am. 1975;57(6):871.

6. Fordyce A. False aneurysm of the profunda femoris artery following nail and plate fixation of an intertrochanteric fracture. Report of a case. J Bone Joint Surg Br. 1968;50(1):141-3.

7. Wolfgang GL, BarnesWT, Hendricks GL. False aneurysm of the profunda femoris artery resulting from nail-plate fixation of intertrochanteric fractures. Clin Orthop Relat Res. 1974;(100):14350 .

8. Ebong WW. False aneurysm of the profunda femoris artery following internal fixation of an intertrochanteric femoral fractures. Injury. 1978;9(3):249-51.

9. Corriere MA, Guzman RJ. True and false aneurysms of the femoral artery. Semin Vasc Surg. 2005;18(4):216-23. 
10. Barquet A, Gelink A, Giannoudis PV. Proximal femoral fractures and vascular injuries in adults: incidence, aetiology and outcomes. Injury. 2015;46(12):2297-313.

11. Segal D, Yaacobi E, Marom N, Feldman V, Aliev E, Palmanovich E, et al. The incidence of lifethreatening iatrogenic vessel injury following closed or open reduction and internal fixation of intertrochanteric femoral fractures. International Orthop. 2017;41(9):1845-50.

12. Miladi M, Kedous MA, Zaraa M, Lahmar AA, Sayed W, barek MM. Pseudoaneurysm of the Profunda Femoris Artery Following Internal Fixation for Intertrochanteric Fracture: A Report of 2 Cases and Review of the Literature. Ortho Res Online J. 2019;5(2):470-1.

13. Yang KH, Park HW, Park SJ. Pseudoaneurysm of the superficial femoral artery after closed hip nailing with a Gamma nail: report of a case. J Orthop Trauma. 2002;16:124-2.

14. Regus S, Lang W. Arterial injury and pseudoaneurysm formation after lesser trochanter fracture. Int J Surg Case Rep. 2015;14:4-6.

15. Georgiannos D, Lampridis V, Bisbinas I. Complications following treatment of trochanteric fractures with the gamma3 nail: Is the latest version of gamma nail superior to its predecessor? Surg Res Pract. 2014;2014:3598.

Cite this article as: Jain VT, Katariya J, Archik S. Pseudoaneurysm of profunda femoris artery: a rare complication after intramedullary fixation for an intertrochanteric femur fracture. Int J Res Orthop 2019;5:969-73. 